\title{
Seasonal Changes in Physical Fitness of Adolescent Track and Field Athletes
}

\author{
AYA MIYAMOTO*1), TOSHIO YANAGIYA*2) \\ *1) Faculty of Health and Sports Science, Juntendo University, Chiba, Japan,*2) Graduate of Health and Sports Science, \\ Juntendo University, Chiba, Japan
}

\begin{abstract}
Introduction: Athletic season is roughly divided into three seasons in Japan, namely the physical training season in winter, the pre-competition season in spring and the competition season between summer and autumn. Therefore, it is generally thought that aims, contents, volume, and programs of workout are different by seasons. For that reason, physical fitness levels of athletes may fluctuate through a year. Thus, the purpose of this study was to identify seasonal changes in physical fitness of adolescent track and field athletes.

Methods: Subjects were 11 boys and 7 girls of two different high schools. Tests are performed in each season. We applied assessments of physical fitness: $100 \mathrm{~m}$ sprint running, three kinds of vertical jump (squat jump, counter movement jump, and drop jump), single-joint isometric torque (knee extension, knee flexion, dorsiflexion, and plantar flexion), and anthropometric characteristics.

Results: Friedman test and post hoc Wilcoxon test revealed that many of physical fitness parameters of boy athletes were higher at the competition season compared with in the other seasons. In girls, only counter movement jump and body weight were significant differences among seasons.

Discussion: This study was found that physical fitness of adolescent track and field athlete varied through seasons. Especially, it was trend to improvement of the muscle strength and power output in the competition season.

Conclusion: Seasonal changes were found in physical fitness of adolescent track and field athletes. Moreover, sex differences were found in the trends in seasonal changes.
\end{abstract}

Key words: seasonal changes in physical fitness, adolescent athlete, sprint running performance

\section{Introduction}

It could be said necessary to improve physical fitness in order to reach a high level of competition in track and field events. In previous studies of focused on sprint running performance, had reported relationship with leg strength and/or jump performance ${ }^{1)-3)}$. In addition, athletes could be required to decrease amount of body fat as well as increase the muscle mass.

Field tests have been carried out for assessments of physical fitness in the coaching field. In particular, the importance and significance of assessments of physical fitness for adolescent athlete have been pointed out. Barker et al. ${ }^{4)}$ had indicated that it is important in order to evaluate advantages and weakness, effectiveness of a training programs, and predictive future performance.

We consider to be effective for evaluation of training effects among many significances. Because previous studies had been shown that there are differences in training effect by age. Pesta $e t$ al. ${ }^{5}$ had found that adolescents were shown higher muscular adaptations of 10 -week resistance training compared with adults. And Amigo et al. ${ }^{6}$ had reported that response to training and detraining were higher the 16-year group than 14-year and 15-year. Therefore, it would need assessments of physical fitness that take account of the training period.

Corresponding author: Aya Miyamoto

Faculty of Health and Sports Science, Juntendo University

1-1 Hirakagakuendai, Inzai-shi, Chiba 270-1695, Japan

TEL: +81-476-98-1001 (ext. 426) FAX: +81-476-98-1011 E-mail: a-miyamoto@juntendo.ac.jp

The $2^{\text {nd }}$ Congress, International Academy of Sportology 〔Held on Sep. 12, 2015〕

[Received Dec. 21, 2015] 
Athletic season is roughly divided into three seasons in Japan. There are namely the physical training season in winter, the pre-competition season in spring, and the competition season between summer and autumn. Therefore, it is generally thought that aims, contents, volume, and programs of workout are different by seasons. Although priority of workout vary depending on coaches, characteristics of workout for each season can be shown generally as follows. In the physical training season, workouts are aimed to improve muscle mass, strength, and muscular endurance. Improvement of power output is one of the aim of important in the pre-competition season. In the competition season, a lot of time are spent on technical training and conditioning. These differences might lead seasonal changes in physical fitness of adolescent athletes. In a review of "Seasonal variation in fitness parameters in competitive athletes" by Koutedakis ${ }^{7)}$, had reported that the swings in fitness variables may be as high as $18 \%$ from one season to another. And, it had been mentioned to be depended on performance levels, the type of sports and the fitness parameters in question. However, there is little information about adolescent athletes of track and field events.

There is a limit to evaluate as sprint running predictors, since these were based on cross sectional studies. The longitudinal research of this study will be able to get additional knowledge of previous studies. Evaluating seasonal changes of physical fitness can be utilize as individual workout prescription and coaching. The purpose of this study was to identify seasonal changes in physical fitness of adolescent athletes in track and field. It was hypothesized that physical fitness levels of athletes may fluctuate through a year.

\section{Methods}

\section{Subjects}

Subjects were 11 boys ( $16.4 \pm 0.6$ years, 171.9 $\pm 5.1 \mathrm{~cm}, 60.8 \pm 5.2 \mathrm{~kg}$; at the first test) and 7 girls $(16.8 \pm 0.5$ years, $160.7 \pm 3.6 \mathrm{~cm}, 51.5 \pm$ $4.1 \mathrm{~kg}$; at the first test). All subjects belonged to two different high school's track and field club, and had trained 6 days per week through a year. Participating both athletes and their parents received detailed information about the study, and they gave their written informed consent.

\section{Testing procedures}

Tests were performed three times a year for each seasons; the physical training season in end of November to December, the pre-competition season in March, and the competition season in August. The survey was carried out over a period of two years. We applied assessments of physical fitness: $100 \mathrm{~m}$ sprint running, three kinds of vertical jump, single-joint isometric torque, and anthropometric characteristics. Order of tests were random in each of subject and time of measurements.

All subjects performed $100 \mathrm{~m}$ sprint running from a block start with spike shoes at athletics track field once. Sprint time (100 m time) was calculated from digital video camera frames $(30 \mathrm{~Hz})$.

Jump height of three kinds of vertical jump (squat jump; SQJ, counter movement jump; CMJ, and drop jump from height of 30-50cm; DJ30, DJ40, DJ50) were measured with MULTI JUMP TESTER (PTS-102, DKH Co., Ltd., JAPAN). Figure-1 (A, B, and $C$ ) shows examples of each jump modalities. All subjects were instructed to jump as high as possible, and were not allowed to use their arms. The highest score in 2 trials were accepted as the jump scores.

Single-joint isometric torque of knee extension (KE TQ), knee flexion (KF TQ), dorsiflexion (DF $\mathrm{TQ}$ ), and plantar flexion (PF TQ) of the right side were measured with an isometric dynamometer. $\mathrm{KE} \mathrm{TQ}$ and KF TQ were measured in sitting position with 90 degrees of their hip and knee joint angles. The attachment pad fixed the lower leg, and set to match the rotation axis of the knee joint center and the torque meter. $\mathrm{DF}$ TQ and $\mathrm{PF}$ TQ were measured in long sitting position with 90 degrees of their hip and 180 degrees of knee joint angles. And sets of ankle angle were at 110 degrees in measurement of $\mathrm{DF} \mathrm{TQ}$, and at 90 degrees in measurement of PF TQ. Then, all subjects performed voluntary isometric contractions as explosively as possible and attempted to maintain the maximum force for 3 seconds. The highest score in 2 trials were accepted as the TQ scores, and relative TQ to body weight was evaluated.

Assessments of anthropometric characteristics were height, body weight, subcutaneous fat thickness, and muscle thickness. Measurements of 
(A) SJ

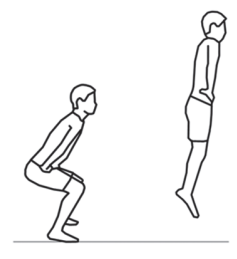

(B) $\mathrm{CMJ}$

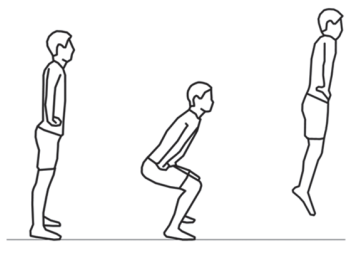

(C) DJ30, DJ40, and DJ50

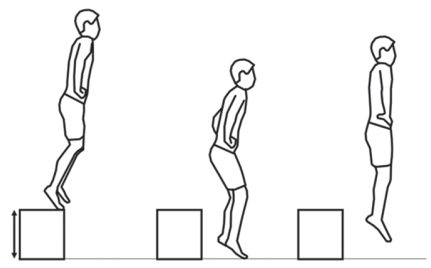

Figure-1 Examples of vertical jump modalities

A. SJ: squat jump, B. CMJ: counter-movement jump, C. DJ30, DJ40, and DJ50: drop jump from height of 30-50 cm.

subcutaneous fat thickness and muscle thickness at right side were used B-mode ultrasonic apparatus. From these results, percent of body fat (\% Body fat) and fat-free mass were estimated from equation by Abe et al. ${ }^{8)}$.

\section{Statistical analysis}

All measurement values are presented as mean \pm standard deviation values (mean $\pm \mathrm{SD}$ ). Seasonal changes were assessed with Friedman test and post hoc Wilcoxon test to each sex. A p-value of $<0.05$ was used to indicate statistical significance.

\section{Results}

Table- 1 shows descriptive data on physical fitness of boy athletes. There were significant differences among seasons in many of physical fitness parameters of boy athletes. $100 \mathrm{~m}$ Sprint running at the competition season was faster compared with in other seasons. Similarly, DJ50, KF TQ, and DF TQ at the competition season was higher. In anthropometric characteristics, body weight at the pre-competition season was higher compared with in other seasons. And fat-free mass at the competition season was higher than the physical training season.

Table-2 shows descriptive data on physical fitness of girl athletes. Girl athletes were found that only CMJ and body weight were significant differences among seasons. CMJ at the physical training season was lower compared with in other seasons. And body weight at the pre-competition season was higher.

\section{Discussion}

This study primarily aimed to identify seasonal changes in physical fitness of adolescent athletes in track and field event. Results of this study indicated that physical fitness were seasonal changes in adolescent track and field athletes of each sex. Moreover, sex differences were seen in the trend. In boy athletes, $100 \mathrm{~m}$ sprint running was improved at the competition season. In addition, DJ50, KF TQ, and DF TQ were also increased. On the other hand, seasonal changes of girl athletes were limited in physical fitness parameters.

Sex differences about the trend of seasonal changes would be expected that differed in workouts, trainability and growth. First, workouts were not a little difference between boy and girl athletes. All subjects had completed almost same contents, volume, and programs of workout of their each high school through a year. Next, it is about differences in trainability by sex. In previous studies, sex differences had not found ${ }^{9)}$. Relative changes in the strength and muscle hypertrophy that occurred as a 16 -week results of the heavy-resistance training were similar in men and women ${ }^{9)}$. Although, this study showed sex differences in an outcome of training in the adolescent track and field athletes. These results may indicate the necessary to divide by sex in training. Lastly, it is about influences of growth for physical fitness. Kanehisa et al. ${ }^{10)}$ had shown that CSA of the lower leg muscles were difference by sex after 13-15 years. And sex differences in DF and PF of strength became apparent in 16-18 year age group. However, they had considered that sex differences in muscle CSA and strength during growth could be accounted for by differences in the lower leg length and muscle mass. In sprint speed improvement, sex 
Table-1 Descriptive data on physical fitness test of boy athletes (Mean $\pm \mathrm{SD}$ )

\begin{tabular}{lcccc}
\hline & Test 1 & Test 2 & Test 3 & $\mathrm{p}<0.05$ \\
\hline 100 m time $(\mathrm{sec})$. & $12.2 \pm 0.3$ & $12.2 \pm 0.4$ & $11.9 \pm 0.4$ & Test $1,2>$ Test 3 \\
SJ $(\mathrm{cm})$ & $37.4 \pm 4.4$ & $38.2 \pm 4.0$ & $39.3 \pm 4.1$ & \\
CMJ $(\mathrm{cm})$ & $43.9 \pm 3.3$ & $43.5 \pm 2.7$ & $44.2 \pm 4.2$ & \\
DJ30 $(\mathrm{cm})$ & $34.4 \pm 6.2$ & $35.2 \pm 6.0$ & $37.1 \pm 4.7$ & \\
DJ40 $(\mathrm{cm})$ & $35.2 \pm 5.6$ & $36.8 \pm 5.7$ & $39.3 \pm 5.5$ & \\
DJ50 $(\mathrm{cm})$ & $35.1 \pm 5.8$ & $36.3 \pm 5.7$ & $39.9 \pm 4.8$ & Test $1,2<$ Test 3 \\
KE TQ $(\mathrm{Nm} / \mathrm{kg})$ & $2.54 \pm 0.31$ & $2.55 \pm 0.31$ & $3.09 \pm 0.23$ & \\
KF TQ $(\mathrm{Nm} / \mathrm{kg})$ & $1.90 \pm 0.34$ & $1.81 \pm 0.29$ & $2.20 \pm 0.13$ & Test $1,2<$ Test 3 \\
DF TQ $(\mathrm{Nm} / \mathrm{kg})$ & $0.66 \pm 0.00$ & $0.65 \pm 0.00$ & $0.70 \pm 0.00$ & Test $1,2<$ Test 3 \\
PF TQ $(\mathrm{Nm} / \mathrm{kg})$ & $2.84 \pm 0.64$ & $2.65 \pm 0.65$ & $3.16 \pm 0.34$ & \\
Height $(\mathrm{cm})$ & $171.9 \pm 5.1$ & $172.1 \pm 5.1$ & $172.0 \pm 5.1$ & \\
Body weight $(\mathrm{kg})$ & $60.8 \pm 5.2$ & $62.2 \pm 4.9$ & $61.0 \pm 5.3$ & Test $1,3<$ Test 2 \\
\%Body fat & $10.3 \pm 0.7$ & $10.4 \pm 0.8$ & $10.3 \pm 1.0$ & \\
Fat-free mass $(\mathrm{kg})$ & $52.6 \pm 4.8$ & $53.4 \pm 4.0$ & $53.9 \pm 3.9$ & Test $1<$ Test 3 \\
\hline
\end{tabular}

Table-2 Descriptive data on physical fitness test of males (Mean \pm SD)

\begin{tabular}{lcccc}
\hline & Test 1 & Test 2 & Test 3 & $\mathrm{p}<0.05$ \\
\hline 100 m time $(\mathrm{sec})$ & $13.6 \pm 0.6$ & $13.7 \pm 0.6$ & $13.5 \pm 0.5$ & \\
SJ $(\mathrm{cm})$ & $30.7 \pm 1.2$ & $32.2 \pm 2.5$ & $32.1 \pm 1.9$ & \\
CMJ $(\mathrm{cm})$ & $34.3 \pm 3.5$ & $37.5 \pm 3.4$ & $37.3 \pm 3.4$ & Test 1<Test 2,3 \\
DJ30 $(\mathrm{cm})$ & $32.3 \pm 3.0$ & $33.0 \pm 4.3$ & $34.8 \pm 3.7$ & \\
DJ40 $(\mathrm{cm})$ & $32.7 \pm 3.4$ & $32.9 \pm 3.7$ & $34.9 \pm 3.1$ & \\
DJ50 $(\mathrm{cm})$ & $33.4 \pm 4.3$ & $33.0 \pm 3.8$ & $34.9 \pm 4.0$ & \\
KE TQ $(\mathrm{Nm} / \mathrm{kg})$ & $2.47 \pm 0.26$ & $2.44 \pm 0.05$ & $2.64 \pm 0.25$ & \\
KF TQ $(\mathrm{Nm} / \mathrm{kg})$ & $1.96 \pm 0.12$ & $1.74 \pm 0.30$ & $1.96 \pm 0.16$ & \\
DF TQ $(\mathrm{Nm} / \mathrm{kg})$ & $0.54 \pm 0.01$ & $0.54 \pm 0.01$ & $0.58 \pm 0.00$ & \\
PF TQ $(\mathrm{Nm} / \mathrm{kg})$ & $2.63 \pm 0.37$ & $2.55 \pm 0.29$ & $2.70 \pm 0.02$ & \\
Height $(\mathrm{cm})$ & $160.7 \pm 3.6$ & $160.9 \pm 3.4$ & $161.0 \pm 3.7$ & \\
Body weight $(\mathrm{kg})$ & $51.5 \pm 4.1$ & $52.9 \pm 4.2$ & $50.3 \pm 4.6$ & Test $1,3<$ Test 2 \\
\%Body fat & $15.5 \pm 1.6$ & $15.9 \pm 2.3$ & $14.9 \pm 1.9$ & \\
Fat-free mass $(\mathrm{kg})$ & $40.4 \pm 2.8$ & $41.2 \pm 3.2$ & $41.2 \pm 2.5$ & \\
\hline
\end{tabular}

difference was more obvious and reached the significance level after the age of $15^{11)}$. Subjects of this study were the age from 15 to 18 , consistent with the age which sex differences were observed in previous study. The trend of seasonal changes by sex may be influence of growth.

Seasonal changes of anthropometric characteristics were similar trend in both boys and girls. Body weight was increased at the pre-competition season, then decreased at the competition season. Moreover, the average value of the fat-free mass at the pre-competition season was higher than the physical training season, and it was kept in the competition season. However, seasonal change of the free-fat mass was not significant difference. These results were suggested that athletes were increasing the muscle mass as well as decreasing amount of body fat towards the competition.

Measured physical fitness of this study have been used as the parameters of sprint running, because the correlation had been found in previous studies ${ }^{1-3)}$. Alexander ${ }^{12)}$ had indicated significant relationships between sprinting times of $100 \mathrm{~m}$ and peak torque scores of knee extension and 
dorsiflexion in elite sprinters. In addition, Smirniotou et $a{ }^{1}{ }^{1)}$ had been manifested that the best predictors of the $100 \mathrm{~m}$ sprint running is probably SQJ or CMJ. In the results of this study, physical fitness were higher when $100 \mathrm{~m}$ time was the fastest in all of the seasons. This may be mean that it was similar results with cross sectional studies of previous studies. These findings revalidated that $100 \mathrm{~m}$ sprint running is associated with vertical jump performance and leg strength.

This study found that boy athletes improved many of physical fitness parameters at the competition season. These would reflect training effects during season. And it was suggested that workouts in the competition season can be enhance essential physical fitness to the competition for track and field sprint events. All subjects of this study were either sprinter and/or jumper. In general, sprint running trainings increase frequency as well as quantity of intensity during the pre-competition season and the competition season. Markovic et $a l .{ }^{13)}$ had reported that sprint running training was caused improvements in leg power output and dynamic athletic performance. Therefore, future research will be necessary to evaluate workouts in more detail by recording, such as contents, volume, and programs.

\section{Conclusion}

Seasonal changes in physical fitness of adolescent Track and Field athletes were found. And sex differences were seen in the trend to seasonal changes.

\section{Reference}

1) Smirniotou A, Katsikas C, Paradisis G, Argeitaki P, Zacharogiannis E, Tziortzis S: Strength-power parameters as predictors of sprinting performance. J Sports Med Phys Fitness, 2008; 48: 447-454.

2) Aerenhouts D, Debaere S, Hagman F, Van Gheluwe B, Delecluse C, Clarys P: Influence of physical development on start and countermovement jump performance in adolescent sprint athletes. J Sports Med Phys Fitness, 2013; 53: 1-8.

3) Young W, McLean B, Ardagna J: Relationship between strength qualities and sprinting performance. J Sports Med Phys Fitness, 1995; 35: 13-19.

4) Barker AR, Armstrong N: Exercise testing elite young athletes. Med Sport Sci, 2011; 56: 106-125.

5) Pesta D, Thaler A, Hoppel F, Macek C, Schocke M, Burtscher M: Effects of a 10-week conventional strength training program on lower leg muscle performance in adolescent boys compared to adults. J Sports Med Phys Fitness, 2014; 54: 147-153.

6) Amigo N, Cadefau JA, Ferrer I, Tarrados N, Cussó R: Effect of summer intermission on skeletal muscle of adolescent soccer players. J Sports Med Phys Fitness, 1998; 38: 298-304.

7) Koutedakis Y: Seasonal variation in fitness parameters in competitive athletes. Sports Med, 1995; 19: 373-392.

8) Abe T, Kondo M, Kawakami Y, et al: Prediction equations for body composition of Japanese adults by M-mode ultrasound. Am J Hum Biol, 1994; 6: 161-170.

9) Cureton KJ, Collins MA, Hill DW, Mchelhannon FM Jr: Muscle hypertrophy in men and women. Med Sci Sports Exerc, 1988; 20: 338-344.

10) Kanehisa H, Yata H, Ikegawa S, Fukunaga T: A cross-sectional study of the size and strength of the lower leg muscles during growth. Eur J Appl Physiol, 1995; 72: 150-156.

11) Papaiakovou G, Giannakos A, Michailidis C, et al: The effect of chronological age and gender on the development of sprint performance during childhood and puberty. J Strength Cond Res, 2009; 23: 2568-2573.

12) Alexander MJL: The relationship between muscle strength and sprint kinematics in elite sprinters. Can J Spt Sci, 1989; 14: 148-157.

13) Markovic G, Jukic I, Milanovic D, Metikos D: Effects of sprint and plyometric training on muscle function and athletic performance. J Strength Cond Res, 2007; 21: 543-549. 